The State of Law

$d|u| p$ 



\section{The State of Law}

Comparative Perspectives on the Rule of Law in Germany and Vietnam

\section{Ulrich von Alemann/Detlef Briesen/ Lai Quoc Khanh (eds.)}


Gefördert und gedruckt mit Unterstützung der Gerda Henkel Stiftung, der AntonBetz-Stiftung der Rheinischen Post und der Gesellschaft von Freunden und Förderern der Heinrich-Heine-Universität Düsseldorf e.V. (GFFU).

Bibliografische Information der Deutschen Nationalbibliothek.

Die Deutsche Nationalbibliothek verzeichnet diese Publikation in der Deutschen Nationalbibliografie; detaillierte bibliografische Daten sind im Internet über http://dnb.dnb.de abrufbar.

\section{(cc) BY-NC-ND}

This work is licensed under the Creative Commons Attribution-NonCommercial-NoDerivs 4.0 License. For details go to http://creativecommons.org/licenses/by-nc-nd/4.0/.

(C) düsseldorf university press, Düsseldorf 2017

http://www.dupress.de

Satz und Layout: Duc-Viet Publikationen

Umschlaggestaltung: Marvin P. Klähn

Lektorat, Redaktion: Detlef Briesen

Druck: KN Digital Printforce GmbH, Ferdinand-Jühlke-Straße 7, 99095 Erfurt.

Der Fließtext ist gesetzt in Garamond $3 \mathrm{FV}$

ISBN: 978-3-95758-053-5

eISBN 978-3-11-072035-8 